\title{
Evaluation of Safety Behavior and Work-related Injuries among Foreign Construction Workers in Malaysia
}

\author{
Haroun Zerguine, (zerguine.har_hse@yahoo.fr) ${ }^{1}$, Shamsul Bahri Bin Mohd Tamrin \\ (shamsul_bahri@upm.edu.com) ${ }^{1}$, Juliana Jalaludin (juliana@upm.edu.com) ${ }^{1}$ \\ ${ }^{1}$ Department of Environmental and Occupational Health, Faculty of Medicine and Health Sciences \\ University Putra Malaysia, 43400 Serdang, Selangor, Malaysia
}

\begin{abstract}
Construction sector is one of the largest sectors in many parts of the world due to the various types of activities taking place onsite as well as the nature of construction work. This particular sector is also regarded as the most dangerous and hazardous workplace. Workers are constantly in contact with dangerous equipment and substances which often affect their health condition. Unsafe behavior of workers, such as human error or inappropriate operation is a major risk factor that occurs across construction projects, and leads to the occurrence of accidents or any related injuries. This study was conducted to investigate safety behavior and work-related injuries in construction projects. 323 construction workers from six different projects in Kang Valley participated in this study. Questionnaire was used to determine the occurrence, severity and causes of work-related injuries. On-site observation using checklist was performed to assess the workers' safety behavior in the workplace. Workers were observed independently in the natural surroundings when carrying out their activities. Wearing Personal Protective Equipment (PPE), housekeeping, access to heights, plant and equipment were measured as safe or unsafe based on the trades and the type of work performed by each worker. The results showed that $22.6 \%$ of the total participants experienced a work-related injury at least once in the last one year period. $17.8 \%$ of the work-related injuries were serious, $39.7 \%$ were moderate and $42.5 \%$ were minor. Falls from height recorded the highest cause of work-related injuries $(31.5 \%)$ followed by lifting and handling (24.7\%). The on-site observation recorded safe and unsafe behaviors from the workers; thus, the overall safety behavior (percent safe) was at $51.62 \%$. The results revealed a significant association between wearing PPE and work-related injuries $\mathrm{t}(321)=7.65, \mathrm{p}<0.001$. Results showed that work-related injuries is significantly associated with handling and storing materials $\left(\chi^{2}=21.107, \mathrm{p}<0.001\right)$, throw objects from heights $\left(\chi^{2}=11.719,89, \mathrm{p}<0.001\right)$, storage of tools and machinery $\left(\chi^{2}=8.027, \mathrm{p}<0.001\right)$, use of ladders $\left(\chi^{2}=11.536, \mathrm{p}<0.001\right)$ and insecure loads $\left(\chi^{2}=7.165\right.$, $\mathrm{p}=0.007)$. Safety behavior was the most significant influencing factor on work-related injuries in construction sites. Therefore, Behavior Based Safety (BBS) program is highly recommended to be implemented in construction projects in order to reduce the occurrence of accidents and work-related injuries in construction sector.
\end{abstract}

Keywords: Construction sector, construction workers, safety behavior, Behavior Based Safety, work-related injuries, accidents

\section{Introduction}

Construction work is one of the most hazardous works in all over the world as evidenced by the high injury and fatality rates, where accidents occur at a substantially higher rate than in construction sector rather than in other industries (Pinto et al., 2011). Laborers in construction are continuously exposed to multiple hazards at different risk levels in their daily tasks. Unsafe behavior of workers, such as human error or inappropriate operation, has been identified as one of the major risk factors that occur across construction projects. Heinrich et al. (1980) estimated that $85 \%$ of accidents and incidents in a workplace could be caused by unsafe acts of workers. Fleming \& Lardner (2002a) accordingly indicated that up to $90 \%$ of all work-place accidents and incidents were attributed to the workers' unsafe behavior. It is clear that unsafe acts and behavior of workers increase the amount of injuries in the workplace. Hence, in order to reduce accidents, there must be a focus in reducing unsafe behaviors or acts during construction work. This way, it is possible to improve safety performance and achieve safety outcomes (Choudhry, 2012; Choudhry \& Fang, 2008). Duff et al.(1994) believed that the BBS approach is the best strategy for changing the behavior and attitude of the workers as well as improving safety performance at construction sites. 
Safety behavior can conceptually refers to the way in which the workers' respond to specific circumstances or situations in the workplace and unsafe behavior can be related to human error or an inappropriate human decision that reduces safety during operations and thus results in accidents, injuries and deterioration of the project schedule (Abreu Saurin et al., 2005, Aksorn \& Hadikusumo, 2008; Teo, Ling, \& Chong, 2005, Choudhry \& Fang, 2008). Researchers have suggested that an effective risk control is based on the individuals' behavior (Fleming \& Lardner, 2002b). Therefore, behavioral approach towards safety is becoming an important practice in safety improvement (Cox, Jones, \& Rycraft, 2004, Choudhry, 2014).

This study aims to evaluate safety behavior and work-related injuries among foreign construction workers in Malaysia. At present there is a limited research in Malaysia on measurement of safety behavior and its association with injuries in construction sites. The objectives of this study is to (a) determine the occurrence of work-related injuries in construction sites, (b) evaluate safety behavior, and (c) determine the relationship between safety behavior and work-related injuries in construction sites.

\section{Method}

A cross sectional study was carried out to evaluate safety behavior and to determine its association with work-related injuries among construction workers. Data was collected from six construction projects of a large company in central Malaysia. 323 foreign construction workers have participated in this study by a simple random sampling technique. A structured and validated questionnaire in English and Malay languages was used to determine the occurrence of work-related injuries among the participants. The questionnaire included "Yes" or "No" questions if the worker experience a work-related injury during the last previous two years, and if yes the worker is asked to select the cause, severity of this injury. Translators to Indonesian and Bangladeshi languages were available during all the survey sessions.

To measure safety behavior, a naturalistic observation was performed in each site. An observation checklist was developed based on the study conducted by Choudhry (2014). 13 items were observed and measured as safe, unsafe or not applicable (N/B) based on the trades and the type of work performed by each worker. The items were categorized into four categories: wearing Personal Protective Equipment (PPE), housekeeping, access to heights and plants and equipment. A test-retest method was conducted and results showed good reliability levels

The data collected through the questionnaire and the on-site observation checklist was coded and analyzed using chi square test and independent t-test by the Statistical Package of Social Science (SPSS for Windows, Version 23.0, 2016). The overall safety behavior was measured as "percent safe", which represent the total percentage of safety behavior (Cooper \& Phillips, 2004). The following formula was used: "Percent safe $=[($ Total safe $) /($ Total safe + Total unsafe)] * 100"

\section{Results}

\section{Socio-demographic characteristics}

The results showed that in the total sample of 323 participants, the mean age is 30.53 years old ranging between 18 to 53 years old where $47.1 \%$ of them are married. Regarding the nationality of workers; $48 \%$ are from Bangladesh and 39\% are from Indonesia. Majority of the participants achieved secondary education $(39.9 \%)$ and $84.8 \%$ of them have a qualification on their current work (Table 1).

Table 1: Socio-demographic characteristics of the respondents

\begin{tabular}{|c|c|c|}
\hline Socio-demographic factors & Frequency (\%) & Mean \pm SD \\
\hline Age (year) & & $30.53 \pm 6.79$ \\
\hline \multicolumn{3}{|l|}{ Marital status } \\
\hline - Single & $117(36.2)$ & \\
\hline - Married & $152(47.1)$ & \\
\hline - Divorced / Windowed & $54(16.7)$ & \\
\hline \multicolumn{3}{|l|}{ Nationality } \\
\hline - Indonesian & $126(39)$ & \\
\hline - Bangladeshi & $155(48)$ & \\
\hline - Pakistan & $25(7.7)$ & \\
\hline - Nepal & $11(3.4)$ & \\
\hline - China & $6(1.9)$ & \\
\hline \multicolumn{3}{|l|}{ Education level } \\
\hline - Not attending school & $50(15.5)$ & \\
\hline - Primary education & $120(37.2)$ & \\
\hline - Secondary education & $129(39.9)$ & \\
\hline - College or higher & $24(7.4)$ & \\
\hline \multicolumn{3}{|c|}{ Working Experience in the company } \\
\hline - 1-2 Years & $44(13.6)$ & \\
\hline - 2-3 Years & $127(39.3)$ & \\
\hline - 3-5 Years & $67(20.7)$ & \\
\hline - More than 5 Years & $85(26.3)$ & \\
\hline \multicolumn{3}{|l|}{ Qualification } \\
\hline - Yes & $274(84.8)$ & \\
\hline - No & $49(15.2)$ & \\
\hline
\end{tabular}

\section{Work-related injuries}

$22.6 \% \quad(n=73)$ of the workers had experienced work-related injuries in the previous two years period. The results had showed also that $17.8 \%$ of the work-related injuries are serious, $39.7 \%$ are moderate and $42.5 \%$ are minor. Falls from height is the highest cause of work-related injuries (31.5\%), (Table 2).

Table 2: The occurrence, severity and causes of work-related injuries 


\begin{tabular}{llc}
\hline Work-related Injuries & Frequency (n) & Percentage (\%) \\
\hline Yes & 73 & 22.6 \\
No & 250 & 77.4 \\
$\quad$ Total & $\mathbf{3 2 3}$ & $\mathbf{1 0 0 . 0}$ \\
Severity (n=73) & & \\
- Serious & 13 & 17.8 \\
- Moderate & 29 & 39.7 \\
- Minor & 31 & 42.5 \\
Causes & & \\
- Falls from height & 23 & 31.5 \\
- Lifting and handling & 18 & 24.7 \\
- Slips and trips & 14 & 19.2 \\
- Struck by objects & 10 & 13.7 \\
- Others (electrocution, trans & 8 & 11 \\
$\quad$ portation, collapses, overex & & \\
ertion) & &
\end{tabular}

\section{On-site observation}

The mean value for safety behavior was $51.62 \pm 18.3$. Independent sample t-test was conducted to compare the means of wearing PPE between those workers who experienced work-related injuries and those who did not. The results show a significant difference in the mean of wearing PPE between the two groups $t(321)=7.65$, $\mathrm{p}<0.001$. The mean of PPE was higher in "No" work-related injuries $(58.93 \pm 21.46)$ as compared to "Yes" work-related injuries $(37.84 \pm 17.95)$. Chi square test was conducted to determine the association between safety behavior items and work-related injuries. Results show that work-related injuries is significantly associated with handling and storing materials $\left(\chi^{2}=21.107, \mathrm{p}<0.001\right)$, throw objects from heights $\left(\chi^{2}=11.719, \mathrm{p}<0.001\right)$, storage of tools and machinery $\left(\chi^{2}=8.027, \quad \mathrm{p}<0.001\right), \quad$ use of ladders $\left(\chi^{2}=11.536\right.$, $\mathrm{p}<0.001)$ and insecure loads $\left(\chi^{2}=7.165, \mathrm{p}=0.007\right)$. Independent sample t-test was conducted to compare mean scores of the overall safety behaviour presented as "percent safe" between workers who reported work-related injuries and those workers who did not report work-related injuries. Results in Table 4.13 show a statistical significant difference in the mean of safety behaviour for $\mathrm{t}(144)=11.62, \mathrm{p}<0.001$. The mean of safety behaviour was lower in "No" work-related injuries (34.77, \pm 13.26$)$ as compared to "Yes" work-related injuries $(56.54, \pm 16.57)$ (table 3$)$.

Table 3: The Association between safety behavior and work-related injuries

\begin{tabular}{|c|c|c|c|c|c|c|}
\hline \multirow{2}{*}{ Variables } & & \multicolumn{2}{|c|}{ Work-related injuries } & \multirow[b]{2}{*}{$\chi^{2 \mathrm{a}}$} & \multirow[b]{2}{*}{$t(d f)^{b}$} & \multirow[b]{2}{*}{$\mathrm{p}$ value } \\
\hline & & No & Yes & & & \\
\hline Wearing PPE & & $58.93 \pm 21.46$ & $37.84 \pm 17.95$ & & $7.65(321)$ & $0.001 * *$ \\
\hline Handling and storing materials & Unsafe & $112 \pm 67.1$ & $55 \pm 32.9$ & 21.107 & & $0.001 * *$ \\
\hline \multirow{2}{*}{ Throw objects from heights } & Unsafe & $88 \pm 67.7$ & $42 \pm 32.3$ & 11.719 & & $0.001 * *$ \\
\hline & Safe & $162 \pm 83.9$ & $31 \pm 16.1$ & & & \\
\hline \multirow{2}{*}{ Use of Ladders } & Unsafe & $98 \pm 68.5$ & $45 \pm 31.5$ & 11.536 & & $0.001 * *$ \\
\hline & Safe & $152 \pm 84.4$ & $28 \pm 15.6$ & & & \\
\hline \multirow{2}{*}{ Insecure loads } & Unsafe & $100 \pm 70.9$ & $41 \pm 29.1$ & 7.165 & & $0.007 * *$ \\
\hline & Safe & $49 \pm 89.1$ & $6 \pm 10.9$ & & & \\
\hline Overall Safety behavior & & $56.54 \pm 16.57$ & $34.77 \pm 13.26)$ & & $11.62(144)$ & $0.001 * *$ \\
\hline
\end{tabular}

\section{Discussion}

Based on the results, the prevalence of work-related injuries was similar to a study done in India, where the prevalence rate of injuries among construction workers was $22.92 \%$ (Shah \& Mehta, 2009). Whereas, this result was higher than the study in Egypt (18.4\%) (Alazab, 2004) and also higher than the study in Ethiopia (38.3\%) (Tadesse \& Israel, 2016). This inconsistency in the prevalence of work-related injuries might be related to the difference between countries in the degree of development, quality of workforce, power of Occupational Safety and Health, diversity of work tasks and complexity of the working conditions. The other reason might be linked to the study population in terms of education level and nationality of the workers (local/foreigner). However, the low prevalence found in this study can also be related to the company's management's high commitment of safety by ensuring a successful implementation of Occupational Safety and Health Management System (OSHMS).

The significant relationship between safety behaviour and work-related injuries that was found I this study was supported by previous studies. Glazner et al. (2005) in his study that explored factors contributing to injuries in construction projects found that safety behaviour had a significant relationship with injuries and considered as an important risk factor of work-related injuries. These findings were similar to the study by Chi, Yang, \& Chen (2009) who found that improper use of PPE is significantly contributing to severe injuries and accidents in construction sites. Although improper use of PPE could be the determinant to severe injuries and 
accidents in construction sites, Aksorn and Hadikusumo (2008) however, discovered that such incidents could be reduced through proper handling of materials and good housekeeping. The study conducted by Chi et al. (2012) had shown that wearing PPE or any other safety devices, handling of tools or equipment, and site inspections were strongly related to both accident type and injury severity.

\section{Conclusion}

In conclusion, human safety behaviour remains to be the main causes of accidents occurrence and work-related injuries in the Malaysian construction industry. This is evident when workers engage in unsafe acts by failing to use Personal Protection Equipment (PPE) such as protective footwear, hearing protection, or fall arresting equipment, whereas, some other workers do practice the use of PPE, but improperly. Therefore, Behavioral Based Safety Program (BBS) is recommended to be implemented in all construction sites in order to improve the workers' safety behavior and reduce the occurrence of injuries in the workplace.

\section{Acknowledgements}

Authors greatly appreciate the cooperation given by the company for allowing the access to construction sites and provided helps in facilitating the data collection process. Besides, authors are grateful to all workers for their willingness to participate in this study.

\section{References}

Abreu Saurin, T., Torres Formoso, C., \& Borges Cambraia, F. (2005). Analysis of a safety planning and control model from the human error perspective. Engineering, Construction and Architectural Management, 12(3), 283-298.

Aksorn, T., \& Hadikusumo, B. H. W. (2008). Critical success factors influencing safety program performance in Thai construction projects. Safety Science, 46(4), 709-727.

Alazab, R. M. A. (2004). Work-related diseases and occupational injuries among workers in the construction industry. African Newsletter on Occupational Health and Safety, 14(2), 37-42.

Chi, C.-F., Yang, C.-C., \& Chen, Z.-L. (2009). In-depth accident analysis of electrical fatalities in the construction industry. International Journal of Industrial Ergonomics, 39(4), 635-644.

Chi, S., Han, S., \& Kim, D. Y. (2012). Relationship between unsafe working conditions and workers' behavior and impact of working conditions on injury severity in US construction industry. Journal of Construction Engineering and Management, 139(7), 826-838.

Choudhry, R. M. (2012). Implementation of BBS and the impact of site-level commitment. Journal of Professional Issues in Engineering Education and Practice, 138(4), 296-304.

Choudhry, R. M. (2014). Behavior-based safety on construction sites: A case study. Accident Analysis \& Prevention, 70, 14-23.

Choudhry, R. M., \& Fang, D. (2008). Why operatives engage in unsafe work behavior: Investigating factors on construction sites. Safety Science, 46(4), 566-584.

Cooper, M. D., \& Phillips, R. A. (2004). Exploratory analysis of the safety climate and safety behavior relationship. Journal of Safety Research, 35(5), 497-512.

Cox, S., Jones, B., \& Rycraft, H. (2004). Behavioural approaches to safety management within UK reactor plants. Safety Science, 42(9), 825-839.

Duff, A. R., Robertson, I. T., Phillips, R. A., \& Cooper, M. D. (1994). Improving safety by the modification of behaviour. Construction Management and Economics, 12(1), 67-78.

Fleming, M., \& Lardner, R. (2002a). Strategies to promote safe behaviour as part of a health and safety management system. HSE Books.

Fleming, M., \& Lardner, R. (2002b). Strategies to promote safe behaviour as part of a health and safety management system. HSE Books.

Glazner, J., Bondy, J., Lezotte, D. C., Lipscomb, H., \& Guarini, K. (2005). Factors contributing to construction injury at Denver International Airport. American Journal of Industrial Medicine, 47(1), 27-36.

Heinrich, H. W., Petersen, D. C., Roos, N. R., \& Hazlett, S. (1980). Industrial accident prevention: A safety management approach. McGraw-Hill Companies.

Pinto, A., Nunes, I. L., \& Ribeiro, R. A. (2011). Occupational risk assessment in construction industry-Overview and reflection. Safety Science, 49(5), 616-624.

Shah, C. K., \& Mehta, H. (2009). Study of injuries among construction workers in Ahmedabad City, Gujarat. Indian $J$ Practising Doctor, 5, 1-5.

Tadesse, S., \& Israel, D. (2016). Occupational injuries among building construction workers in Addis Ababa, Ethiopia. Journal of Occupational Medicine and Toxicology, 11(1), 1.

Teo, E. A. L., Ling, F. Y. Y., \& Chong, A. F. W. (2005). Framework for project managers to manage construction safety. International Journal of Project Management, 23(4), 329-341. 